\title{
CONFERENCE REACTION AND PLAN
}

\author{
David Shulenburger \\ Provost and Executive Vice Chancellor \\ University of Kansas - Lawrence campus
}

At this conference we have heard about the impact of our institutions on people and the quality of life. We've heard the mission statements of the universities. Mary Sue Coleman repeated over and over the importance of our missions having top priority. She is now at a large university in a state with a large population. She gave us a formula for success: look for faculty initiatives and provide institutional support. She talked in numbers, the magnitude of which could make us blush - $\$ 2$ billion in research dollars. She has matched this amount with $\$ 900$ million in support from the state of Michigan. In addition to a lot of support that was directed and targeted - helping the faculty build and organize, doing some cheerleading - there was also some serendipity involved in the receipt of a $\$ 25$ million dollar gift.

Harvey Perlman talked about a larger piece of serendipity in Nebraska. It fell into the pattern of the formula - faculty initiative plus institutional support directed in a functional way to produce an objective. Even in institutions with so many resources and of such scale, what Mary Sue Coleman talked about were five core centers developed in cooperation with other universities in Michigan and funded by the $\$ 2$ billion dollar initiative. Not only were these resources shared among universities, but they were also shared with individuals in Michigan. Note that if there is any institution of sufficient scale and wealth to be self-sufficient, it is the University of Michigan, but a big part of its success is choosing not to be self-sufficient and self-contained. The University of Michigan is willing to work with its neighbors to bring in useful resources.

The presentations that followed Dr. Coleman's repeated the theme of faculty initiative with institutional support. It was interesting that Richard Schiefelbusch did a word count on "passion" in the last talk - that word describes his life. If we had done a word count on "collaboration" we would have rung the meter. We talked a lot about collaboration - how to sustain it and how to imagine new ways to collaborate. I'm glad that Susan Sheridan is here since she is starting a new center - there were lots of examples of success at this conference. George Wilson's account of the continuum of multidisciplinary research, tech transfer, big science, economic development - these efforts cry out for collaboration. They are too big to be accomplished by a single individual.

If collaboration is good within an institution, if it is good within a group of colleagues that share your discipline or share your area of focus from the center point of view, maybe we should consider formal collaboration within the group of states that Robert Barnhill, borrowing liberally from geography and geometry, 
calls the "four-corner" states. It is a virtual corner and that's fine. We share a geographic affinity, and over time, a greater affinity than that.

Since 9/11 our states have begun to see us as economic drivers more than ever before. This is less the impact of 9/11 and more the fact that we can't rely on the usual bases of economic growth and vitality. We need more. If you need something different, you look to the university - we are about as different as you can imagine. We are good for economic growth. Legislators have this idea now and we can nourish that idea and make it grow, or we can squelch it. Robert Hemenway talked about the bioscience institute that will give us a lot of fuel over the next 10 years. If we use it correctly, it can have a huge impact on the economy and the state's resources for doing good in the future.

Unlike the University of Michigan, at least three of the states represented here are low population states. Each of our universities is moderate in scale. We don't have the scale of California, Michigan or Illinois schools. Could we benefit from sharing resources and realizing economies of scale by working together? That is the question. I'm an economist and economists don't usually want to produce cooperation; instead they believe in competition. I'm rare. The conservative king Milton Friedman once touched my head and said, "I forgive you, son!" It's from that perspective that I want to talk about cooperation.

If you are going to have cooperation, you are going to have to come to the table as partners. Being partners often means you must have the ability to contribute to the relationship. Our partnership must include research-extensive universities and publicly-funded, research-extensive medical schools, some of which are separate from the universities. Given that $\mathrm{NIH}$ is where the money is, we need to include medical schools.

Suppose we hired a research team to do a SWOT analysis on this set of schools in our four states, looking at the strengths, weaknesses, opportunities, and threats. A team also could produce a Presidents' plan for faculty and facility coordination. That plan would do the following:

1. Identify the major research opportunities that might be available to us, but which our resources don't enable us to seize. Given our strengths, what is it we can't quite do?

2. Identify the existing faculty, facilities and expertise that would be useful for addressing those problems and would be more useful if shared. For example, at $\mathrm{KU}$ we are developing a structural biology center. We probably would benefit more if there were complementary investments elsewhere in the region and we had the ability to share our center with others in return for access to their unique research facilities.

3. Identify the facilities and the faculty we don't have, but could be more effective if we did.

4. Recommend where such facilities and expertise would best be located among the universities in the region. 
Here are the ground rules: the recommendations would have to improve the research funding potential for all schools. The recommendations could include improving research funding potential for each school, and for the collective arrangement of schools, and involve redistribution of resources across the system. It is not research funding that we are interested in as much as the capacity to deal with real problems that fit the mission of these institutions in ways that will end up affecting the viability of our states.

We should create a prospectus that the universities could use with their individual state legislatures, with their federal delegations, with donors, and with foundations to obtain funding and fill in the gaps to make us more effective. The prospectus should talk about cooperation we are unlikely to achieve if we are limited to the resources a single state can muster. We must convince the legislators across the region to invest regionally instead of uniquely in their own institutions.

If we believe in cooperation, we have a couple of choices: to use this scheme to create complementarity among institutions as we develop plans; or to create interdependence among institutions so that in the long-term, we focus on the really big problems one can only address through cooperation. That is a step too far now, but I don't want to begin down a road without asking how much we value cooperation. The study I call for would show us the value of cooperation.

Steps:

1. Refine the proposal.

2. Send it to the presidents and chancellors of the institutions that fit the set of universities collaborating.

3. Let the presidents and chancellors decide whether they think it is worth proceeding and, if so, have a meeting of presidents, chancellors, provosts, and vice provosts for research.

4. Issue an RFD.

5. Pay for the work to be done.

6. Make a decision based on the results of the study. 